\section{Tagbo BN \\ Uleanya ND \\ Nwokoye IC \\ Eze JC \\ Omotowo IB}

\title{
Mothers' knowledge, perception and practice of childhood immunization in Enugu
}

DOI:http://dx.doi.org/10.4314/njp.v39i3.1

Accepted: 12th January 2012

Tagbo BN ( $\square$ ) Uleanya ND

Nwokoye IC, Eze JC, Omotowo IB

Institute of Child Health, University of Nigeria Teaching

Hospital.

Ituku-Ozalla Enugu, Nigeria.

Email: tagbobeckie@yahoo.com Tel : +2348033096473.

\begin{abstract}
Introduction: Immunization has been shown to be the most successful and cost-effective public health intervention in the $20^{\text {th }}$ century. In the developing world, it does not only prevent about three million child deaths annually, but also has the potential to prevent additional two million deaths if coverage improves. However, immunization coverage has remained low in Nigeria although vaccines are provided relatively free by the government. Efforts have focused on the health worker, health system and logistics with little attention being paid to maternal factors like knowledge, perception, beliefs and practice.

Objectives: To assess mothers' knowledge, perception and practice of routine and campaign immunization in Enugu.

Methods: A structured questionnaire was administered to 207 mothers who have at least one child less than 5 years of age, attending children outpatient and immunization clinics at the University of Nigeria Teaching Hospital, Enugu. Results: Forty-eight per cent of the mothers had tertiary education, $42 \%$ had secondary education, and $9 \%$ had primary education while $1 \%$ had no formal education.

Eighty-two per cent knew that children are immunized to prevent major killer diseases, $14 \%$ and $3.4 \%$ believed it was to prevent all diseases, and to treat diseases respec-

never immunized their children during campaigns. On the other hand, $13 \%$ (27) of mothers had out-rightly rejected immunization during campaign while 85\% (177) had never rejected immunization. The remaining $2 \%$ were not immunized due to reasons other than rejection. More mothers significantly rejected campaign immunization than the number that did not go for routine immunization $(\mathrm{p}=0.000)$. Maternal highest educational level was significantly associated with knowledge of reason for immunization and acceptance of immunization $(\mathrm{p}=0.000)$. Religious denomination was not significantly associated with rejection of campaign immunization ( $\mathrm{p}=0.056)$.

Conclusion: Most mothers studied had good knowledge and positive perception and practice of immunization. However, the Campaign immunization rejection rate was relatively high for the south eastern Nigeria where it is often assumed that non-compliance is not a problem. Similarly, the proportions of mothers with wrong knowledge and poor perception of immunization require policy attention. Maternal education was significantly associated with knowledge and acceptance of immunization. These findings are important in the design and implementation of childhood immunization programmes.
\end{abstract} tively. Most mothers took their children to health facilities for routine immunization $(95.2 \%)$ and also accepted immunization on immunization campaign days (75.4\%). However, $23.6 \%$ had
Keywords: Mothers. Knowledge. Perception. Practice. Immunization. 


\section{Introduction}

Immunization is said to be the most successful and cost-effective public health intervention of the $20^{\text {th }}$ century in terms of number of deaths averted per year. ${ }^{1}$ In the developing world, it does not only prevent about 3 million child deaths per year but also has the potential to avert additional 2 million deaths if immunization programmes are expanded and fully implemented. ${ }^{2}$ Childhood immunization has been reported by Zangene et al to indirectly prevent infectious diseases in adults through herd immunity. ${ }^{3}$ They noted that the use of the pneumococcal protein conjugate vaccine among children reduced the total number of invasive pneumococcal disease (IPD) cases and resulted in a $38 \%$ decrease in the rate of IPD among non-vaccinated elderly adults through herd immunity.

Immunization could be routine or supplemental (immunization campaign). Routine immunization refers to the nationally scheduled regular administration of vaccine dosages to infants at specified ages. Children are usually taken to the health facility by their parents or care givers to receive age-appropriate doses of antigens. In most developing countries, this is only done on specific days of the week to reduce vaccine wastage since the vaccines are supplied in multi-dose vials to reduce cost. The main aim of routine immunization is to deliver a complete number of doses of potent vaccines in a timely, safe and effective way to all children and women $^{3}$, ultimately inducing immunity against targeted diseases. ${ }^{4}$ If implemented, the result is a drastic reduction in the burden of childhood vaccine preventable diseases. $^{5}$

On the other hand, supplemental immunization - also known as immunization campaign - is organized occasionally by governments for the purposes of catch-up immunization, disease eradication/elimination and to avert epidemics. Immunization campaigns became more frequent in the last two decades when WHO launched the polio eradication programme. Immunization campaigns against polio and measles have yielded tremendous results globally and in Nigeria. This has reduced global polio cases from 350,000 in 1988 to 1643 in 2009 (>99\% reduction $)^{6}$, and measles from 871,000 in 1999 to 454,000 in 2004 (48\% reduction). ${ }^{7}$ Some mothers/fathers are known to accept routine immunization but reject campaigns while others reject both due to ignorance. ${ }^{8}$ Despite the success of expanded programme on immunization (EPI), such as eradication of small pox ${ }^{4,7}$ and global lowering of incidence of polio by $99 \%,{ }^{9}$ many vaccine-preventable diseases remain prevalent especially in developing countries. ${ }^{4}$

Vaccine preventable diseases are known to account for approximately $22 \%$ of child deaths in Nigeria, amounting to over 200,000 deaths per year. ${ }^{10}$ However, in Nigeria, as in some other third world countries, immunization coverage is low. ${ }^{11,12}$ Nigeria recorded an abysmal national routine immunization coverage of $12 \%$ in $2003^{13}$, and $36 \%$ in $2006 .{ }^{10}$ In 2009 , Nigeria accounted for about 3.5 million (14\%) of the 23.2 million children worldwide who did not receive 3 doses of DPT vaccine during the first year of life. ${ }^{7}$ This not only impedes disease control, but may consequently diminish public support for vaccination, which may lead to a resurgence of vaccine preventable diseases. ${ }^{5}$ In Nigeria, universal childhood routine immunization is provided free of charge as in some countries of the world. Routine immunization is a key strategy in the polio eradication programme, both in Nigeria and globally. ${ }^{13}$ For Nigeria to achieve millennium development goal of reducing child mortality by two-thirds by 2015 , routine immunization coverage must be optimal. ${ }^{13} \mathrm{~A} \mathrm{study}^{14}$ in Colorado demonstrated that children exempted from routine immunization were twenty-two times more likely to acquire measles and almost six times more likely to acquire pertussis than vaccinated children. The primary site for acquiring infection usually, being their schools. The fact that immunization is not $100 \%$ effective, ${ }^{5}$ implies that the choice of some parents not to immunize their children significantly increases the risk of infection for other children who are immunized. ${ }^{5,14}$ This is because a small proportion of vaccinated children would not be protected since sub-optimal immunization coverage reduces herd immunity.

Apart from operational factors relating to policies, vaccine funding, vaccine availability and health workers related factors, some authors ${ }^{4,15}$ have identified awareness, attitude and perception of parents/care givers as major obstacles to high immunization coverage. McCormick et $\mathrm{al}^{16}$ noted that programmes to increase immunization rates have been developed and implemented based on untested hypothesis about why parents do not immunize their children. They are of the view that such implementers ignore the knowledge, awareness, attitudes, beliefs and circumstances of under immunized populations. No study known to the authors has examined these maternal factors in this part of the country. In spite of efforts directed at solving operational problems, immunization coverage in Nigeria has persistently remained unacceptably low. ${ }^{11,12}$

It has therefore become necessary to examine these maternal issues in relation to immunization (routine and campaign) as well as associated factors. The aim of the current study is therefore to assess Mothers' knowledge, perception and practice of childhood immunization in Enugu.

\section{Materials/Method}

This is a cross-sectional descriptive study that was conducted at the children's clinic of University of Nigeria Teaching Hospital (UNTH), Ituku-Ozalla between May and July 2009. The children's clinic consists of the curative section - the children outpatient clinic (CHOP), and the preventive section for well children - the Institute of child Health (ICH) well child clinic, UNTH, Enugu. 
Data was collected consecutively from mothers with at least one child less than five years old attending either section of the clinic, using a structured semi-closed ended interviewer administered questionnaire. Trained interviewers administered the questionnaires in English language, Igbo and pidgin English depending on the respondent's preference. Data collected from mothers included mother's age, mother's highest educational level, reasons for immunizing children and names of target killer diseases. Others were; if she took her children on time for routine immunization or delayed, reasons for any delay, if she immunized her children during immunization campaigns and if she had ever rejected immunization for her child/children.

The inclusion criteria were: mothers with at least one child less than five years of age, and mothers who consented to participate. Exclusion criteria included mothers who did not consent despite adequate explanation, and mothers whose child/children were older than five years. Ethical approval was obtained from the Hospital Ethics Committee and informed consent obtained from mothers. Data entry and analysis were done using Microsoft Excel 2007, SPSS version 15 and GraphPad Prism 5 software. Data was analyzed as proportion of responses and results presented as tables and charts. Association between variables was tested using the chi square test (or exact Fisher's test, where applicable) and level of significance was set at $\mathrm{p}<0.05$.

\section{Results}

Two hundred and seven mothers were recruited into the study. Ninety-four mothers $(45.4 \%)$ were aged $18-29$ years while $113(54.6 \%)$ were aged 30 or above. Almost half of the mothers (48\%) had formal education up to tertiary level, $42 \%$ up to secondary school level and 9\% had only primary education. One per cent had no formal education.

More than a third of mothers $(35.7 \%)$ who participated in this study were traders, $31.9 \%$ were civil servants, housewives constituted $19.8 \%$, while $2.9 \%$ were teachers. Farmers were $2.4 \%$ and others (mainly students) were $7.2 \%$. One hundred and twenty-eight mothers (61.8\%) were Catholics and there was no Muslim respondent. A total of 86 mothers $(41.5 \%)$ had one child less than 5 years (Table 1).

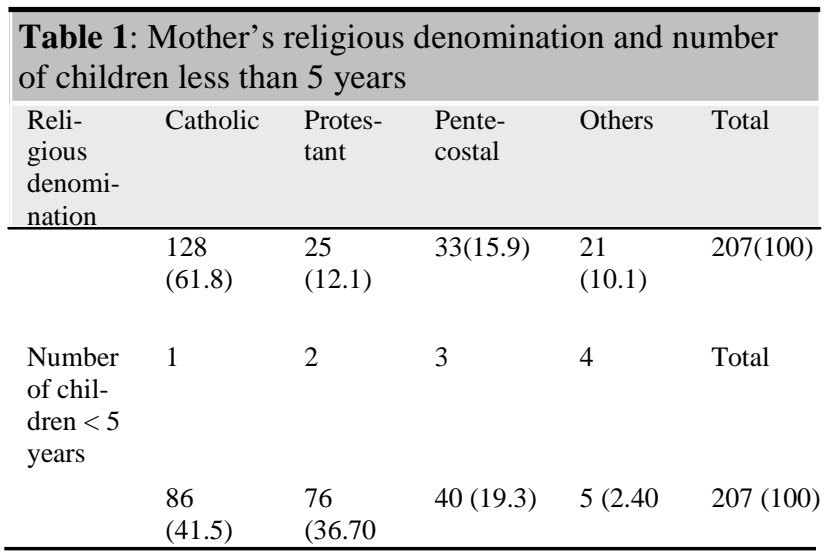

Fig 1: Reason for immunization

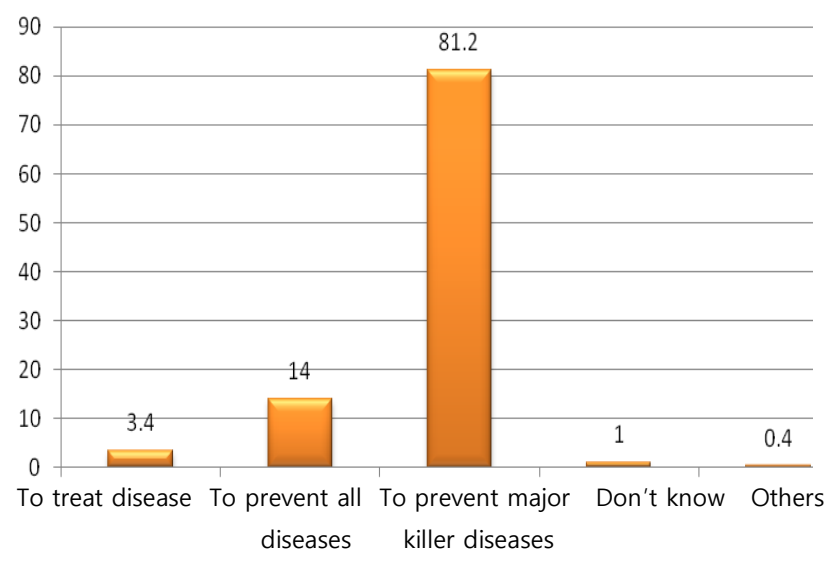

One hundred and sixty-eight mothers $(81.2 \%)$

mentioned the prevention of major killer diseases as the reason for immunization, $17.4 \%$ said that children are immunized to prevent or treat all diseases (Figure 1). A total of $194(93.4 \%)$ mothers were able to mention at least two of the killer diseases correctly (Figure 2) and $94 \%$ believed that routine immunization was worth it. One hundred and ninety five mothers $(95.2 \%)$ took their children to immunization centres to be immunized and out of this number, $82.6 \%$ (171) did so at the appropriate age. Table 2 shows the statistical significance of association between maternal education and several variables related to childhood immunization. 
Table 2: Association between mother's educational level and other variables of immunization

Mother's highest educational level

\begin{tabular}{|c|c|c|c|c|c|c|}
\hline & & Nil/Pri ${ }^{+}$ & $\mathrm{Sec}^{++}$ & Ter $^{+++}$ & Chisquare, df $*^{*+}$ & P-value \\
\hline Reason for immunization & $\begin{array}{l}\text { Wrong } \\
\text { Correct }\end{array}$ & $\begin{array}{l}7 \\
15 \\
22\end{array}$ & $\begin{array}{l}24 \\
62 \\
86\end{array}$ & $\begin{array}{l}8 \\
91 \\
99\end{array}$ & $14.54,2$ & 0.001 \\
\hline Killer diseases & $\begin{array}{l}2 \text { correct } \\
1 \text { correct } \\
\text { Both wrong }\end{array}$ & $\begin{array}{l}3 \\
5 \\
8\end{array}$ & $\begin{array}{l}44 \\
15 \\
28\end{array}$ & $\begin{array}{l}83 \\
7 \\
8\end{array}$ & $39.99,4$ & $<0.000$ \\
\hline Take child at apprage & $\begin{array}{l}\text { Yes } \\
\text { No }\end{array}$ & $\begin{array}{l}14 \\
7\end{array}$ & $\begin{array}{l}66 \\
19\end{array}$ & $\begin{array}{l}88 \\
11\end{array}$ & $7.603,2$ & 0.022 \\
\hline $\begin{array}{l}\text { Ever rejected campaign im- } \\
\text { munization }\end{array}$ & $\begin{array}{l}\text { Yes } \\
\text { No }\end{array}$ & $\begin{array}{l}4 \\
16\end{array}$ & $\begin{array}{l}13 \\
72\end{array}$ & $\begin{array}{l}10 \\
88\end{array}$ & $1.886,2$ & 0.389 \\
\hline Take child for immunization & $\begin{array}{l}\text { Yes } \\
\text { No }\end{array}$ & $\begin{array}{l}\text { Nil/pri/sec } \\
99 \\
5\end{array}$ & $\begin{array}{l}\text { Ter } \\
97 \\
2\end{array}$ & $\begin{array}{l}\text { P value* } \\
0.446\end{array}$ & $\begin{array}{l}\mathbf{R} \mathbf{R}^{* *} * \\
0.707\end{array}$ & $\begin{array}{l}\mathbf{9 5 \%} \mathbf{C I}^{+} \\
0.434-1.15\end{array}$ \\
\hline
\end{tabular}

${ }^{+}$Primary ${ }^{++}$Secondary ${ }^{+++}$Tertiary $*{ }^{+}$Degree of freedom $*$ Fisher's exact test $* *$ Relative risk ${ }^{+}$Confidence interval

Fig 2: Mother's knowledge of two target killer diseases

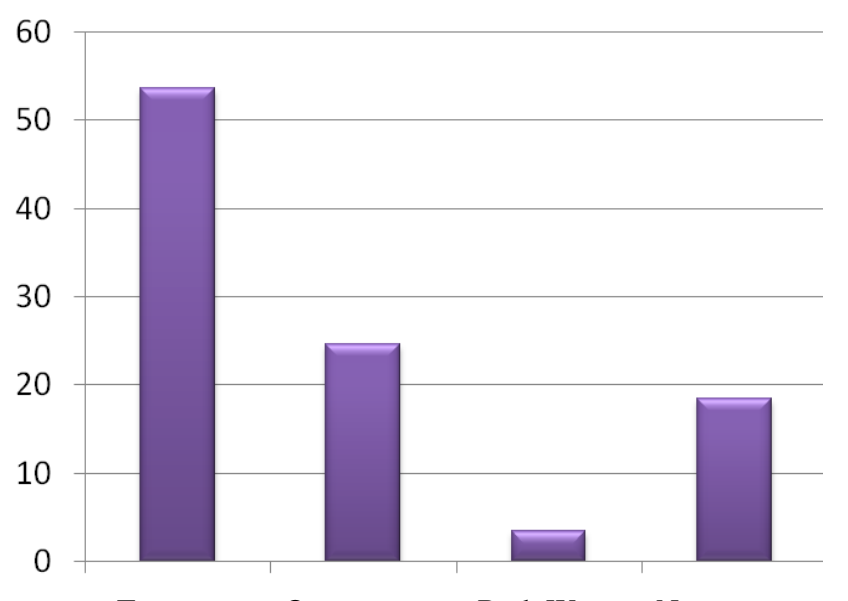

Ninety-five percent (197) of mothers took their children to immunization centres to be immunized, $1 \%$ (2) did not while the rest took only some of their children to be immunized. Thirty-six mothers $(17.4 \%)$ did not immunize their children at the appropriate age due to child's ill-health, unavailability of vaccines or fears of adverse events, among other reasons. Ninety-nine percent of mothers wanted routine immunization to continue. They however identified problems experienced during immunization as, not being attended to on time, long queues, fever and crying after immunization as well as negative attitude of the providers. Civil servants were more likely to take their children for immunization at the appropriate age than traders and house wives ( $\mathrm{p}=0.000$, Table 3 ). Religious denomination did not significantly affect immunization campaign rejection (Table 4) and there was no Muslim respondent.

Two correct One correct Both Wrong No response

Table 3: Mother's occupation and age-appropriate immunization

\begin{tabular}{lllllllll} 
& & $\begin{array}{l}\text { House } \\
\text { wife(\%) }\end{array}$ & Teacher & Trader & $\begin{array}{l}\text { Civil } \\
\text { servant }\end{array}$ & Farmer & others & $\begin{array}{l}\text { P value/likelihood } \\
\text { ratio }\end{array}$ \\
\hline $\begin{array}{l}\text { Take child } \\
\text { at apprage }\end{array}$ & Yes & $33(80)$ & $6(100)$ & $56(79)$ & $61(92)$ & $2(67)$ & $13(87)$ & 0.000 \\
& No & $8(20)$ & $0(0)$ & $15(21)$ & $5(8)$ & $1(33)$ & $2(13)$ & 0.1 \\
\hline
\end{tabular}

Table 4: Mother's Religious denomination and immunization campaign rejection

\begin{tabular}{llllll} 
Catholic & Protestant & Pentecostal & Others & P value & $\begin{array}{l}\text { Likelihood } \\
\text { ratio }\end{array}$ \\
\hline 19 & 1 & 3 & 2 & 0.528 & 0.506 \\
107 & 24 & 29 & 14 & & \\
\hline
\end{tabular}

On immunization campaigns, 75.4\% (156) of the mothers immunized their children during immunization campaign days while $23.6 \%$ had never immunized during campaigns. On the other hand, 13\% (27) of mothers had out-rightly rejected immunization during campaign while $85 \%$ (177) had never rejected immunization. The remaining $2 \%$ were not immunized due to reasons other than rejection. More mothers significantly rejected campaign immunization than the number that did not go for routine immunization $(\mathrm{p}=0.0126$, Table 5$)$. 
The commonest reasons given for rejection of immunization during campaigns were that mothers preferred going to the hospital for immunization with full evaluation of their children, felt there was no need for additional doses outside the routine doses and they had no confidence on the campaign vaccinators. Religious denomination and mother's educational level were not significantly associated with rejection of immunization during campaigns.

Table 5: Child's routine immunization and rejection of campaign immunization

\begin{tabular}{|c|c|c|c|c|c|c|c|}
\hline & & Yes & No & Total & P value* & $\mathrm{RR}^{* *}$ & $95 \% \mathrm{CI}^{* * *}$ \\
\hline \multirow{3}{*}{$\begin{array}{l}\text { Ever rejected } \\
\text { campaign immu- } \\
\text { nization }\end{array}$} & Yes & 23 & 4 & 27 & 0.0126 & 0.872 & $0.744-1.02$ \\
\hline & No & 170 & 4 & 174 & & & \\
\hline & Total & 193 & 8 & 201 & & & \\
\hline
\end{tabular}

* Fisher's exact test $* *$ Relative risk $* * *$ Confidence interval.

\section{Discussion}

Immunization has undoubtedly made a significant impact on the global public health. However, to achieve maximum benefit, immunization coverage should uniformly reach certain critical levels for different diseases. Achieving this requires not only effort on provision of immunization services, but also optimum utilization of these services by the target population. Mothers of under five children who are the main target of childhood immunization need to be significantly aware of the services and benefits of immunization. Being aware of these benefits and services require a minimum literacy level.

Up to $90 \%$ of mothers in the current study had at least secondary education and about half of that number had tertiary education. This indicates that the population studied was literate. This probably explains why

majority could mention the killer target diseases, say why children are immunized and believe immunization was worth the effort. Most of the mothers with secondary and tertiary education had knowledge of the reason for immunization and the killer diseases protected against by immunization. They were also more likely to take their children to immunization centres for immunization at the appropriate age. They were also more likely to accept immunization during immunization campaigns. This significant impact of maternal education on knowledge, perception and practice of immunization has also been observed by some authors. Kabir et $\mathrm{al}^{17}$ in Dambare, similarly noted that mothers with formal education were more likely to be aware of childhood immunization compared to those who had no formal education. It could then be inferred that the more educated a population is the more it is likely to immunize her children thus resulting in higher immunization coverage. However, this finding is at variance with the study ${ }^{4}$ done in Pilani, India where the literacy rate did not significantly influence immunization coverage rates.

Most mothers studied were civil servants, traders or full time house wives. The civil servants were significantly more likely to take their children to immunization centres for immunization at the appropriate age than traders and house wives. We observe that this finding may have been confounded by literacy or awareness level. It would be expected that the house wife and the trader would have more time to take their children to immunization centres for immunization compared to their civil servant counterparts. This is because the civil servant would need to obtain permission to be absent from work before she is able to go and immunize her child. However, the civil servant may be more aware of the importance of immunization. Also with regards to rejection of immunization in this study, about a quarter of the mothers had never immunized their children during campaigns. This is low compared to $54 \%$ seen in the Danbare study. ${ }^{17}$ This is probably due to a better understanding of the benefits of immunization and higher literacy level in the current study. However, the finding of $13 \%$ rejection rate is high for the south-east of Nigeria where it is often assumed that compliance is very good and indicates the need for improved social mobilization with the aim of improving activities for routine immunization. That more mothers $(13 \%)$ rejected campaign immunization compared to the number that rejected routine immunization (4\%) is statistically significant and should be addressed. This finding is important in policy formulation and requires that attention be focused on the more acceptable routine immunization. It is also more enduring and more available. Also, improvement should be made on the delivery methods for campaign immunization to make it more acceptable. The commonest reason for rejection of campaign immunization was that mothers preferred going to the hospital for immunization where the child would be fully assessed before immunization. Another reason was that mothers did not have confidence on the competence of campaign vaccinators. Additionally, some mothers felt there was no need for their children to have additional vaccine doses outside the routine schedule which the child had already received. This highlights the need for health education of the public and improvement in immunization campaign methods. Religious denomination was also not significantly associated with rejection of immunization during campaigns. This agrees with the finding by Adeyinka et $\mathrm{al}^{18}$ in South-western Nigeria. This may be attributed to the fact that the population studied is dominated by the 
Christian religious denomination. All respondents were non- Muslims. Unavailability of vaccines (1\%) should be avoided by the provision of all antigens at immunization sessions; fears of side effects of immunization $(1.4 \%)$ should be allayed through adequate information about adverse events and means of ameliorating them. It is also very important that mothers are informed on types of vaccines and what each vaccine is able to protect their children against. This is against the finding that $14 \%$ of mothers believed that immunization was to prevent all diseases. Otherwise, failure to meet their expectation of prevention of all diseases may have negative effect on immunization uptake.

Majority of the mothers (94\%) expressed favourable disposition towards routine immunization and this agrees with the finding of Morrissey et $\mathrm{al}^{19}$ where $84 \%$ of mothers were favourably disposed to immunization. However, the fact that some mothers could not name correctly or mentioned only one of the 6 major killer diseases is worrisome. This fact informed the decision of the WHO to accompany the recent massive crossregional vaccination campaigns with health information campaigns. $^{20}$ This indicates the need for improved health education during ante-natal care and immunization activities, improved community participation, mass mobilization, and retraining of community health workers.

This study was hospital based and therefore did not assess the knowledge of mothers in the community. There is need to further carry out a population based study on this topic.

\section{Conclusion}

Most mothers studied had good knowledge and positive perception and practice of immunization. However, the campaign immunization rejection rates are relatively high for the southeastern Nigeria where it is often assumed that non-compliance is not a problem. Similarly, the proportions of mothers with wrong knowledge and poor perception of immunization require policy attention. Maternal education was significantly associated with knowledge and acceptance of immunization. These findings are important in the design and implementation of childhood immunization programmes. More attention should be directed at better understanding of perception, practices and beliefs of mothers on childhood immunization. Measures such as female education, adult literacy programmes, health education campaigns and new or improved immunization campaigns delivery methods should be considered for raising immunization coverage in Nigeria.

\section{Authors' contributions \\ Tagbo BN: Developed research question, questionnaire design, literature review, directed data analysis, write up and general coordination. \\ Uleanya ND: Data collection, literature review, data analysis, write up. \\ Nwokoye JC: Data collection, literature review \\ Eze JC: Data collection, literature review \\ Omotowo IB: Data analysis \\ Funding : None \\ Conflict of interest: None}

\section{References}

1. Gains S. Vaccination is the best protection. American academy of paediatrics healthy children's magazine. Last updated 31/05/2011. Available at http:// www.healthychildren.org/Emglish/ safety-prevention/immunization. Accessed 31/12/2011.

2. United States Agency for International Development. Immunization programs for healthy children. Immunization basics. Available at http://

www.immunizationbasics.jsi.com/. Accessed 31/12/2011.

3. Zangeneh TT, Baracco G, AlTawfiq JA. Impact of conjugate pneumococcal vaccines on the changing epidemiology of pneumococcal infections. Expert Rev Vaccines. 2011; 10: 345-353.
4. Manjunath U, Pareek RP. Maternal Knowledge and Perception about the Routine Immunization Programme - a Study in a Semi-urban Area in Rajasthan. Ind J Med Sci 2003; 57: 158-163.

5. Sanford RK. Vaccine Adverse Events: Separating Myth from Reality. Am Fam Phy 2002; 66: 2110-2113.

6. Obregón R, Chitnis K, Morry C, Feek W, Bates J, Galway M, et al. Achieving polio eradication: a review of health communication evidence and lessons learned in India and Pakistan. Bull WHO 2009; 87: 624-630.

7. WHO/UNICEF Joint news release. Global measles deaths plunge by $48 \%$ over past six years. WHO Media centre. Available at http://www.who.int/ mediacentre/news/releases/2006/pr11/ en/ Accessed 6 Jan 2012.
8. Department For International Development-Transaid. Nigeria: programme for reviving routine immunization in four northern states, 2007-2011. Available at www.transaid.org/project/nigeriaprogramme. Accessed 31/12/2011.

9. CDC. Global Routine Vaccination Coverage, 2009. Morbidity and mortality weekly report 2010; 59: 1367-1371.

10. United States Agency for International Development. Country activities: Nigeria. Immunization basics. Available at http:// www.immunizationbasics.jsi.com/ Country Activities.htm\#Nigeria . Accessed 07/01/2012.

11. Tagbo BN, Onwuasigwe C. missed immunization opportunities among children in Enugu. Niger J Paed 2005; 32: 73-6. 
12. Sadoh AE, Eregie CO. Continuing barriers to optimum immunization uptake in Nigerian children: the role of missed immunization opportunities and inappropriately timed Immunizations. Niger $J$ Paed 2007; 34: 57-61.

13. World Health Organization. Expanded Programme on Immunization. Available at http:// www.who.int/ immunization_delivery/en/. Accessed 07/01/2012.

14. Feikin DR, Lezotte DC, Hamman RF, Salmon DA, Chen RT, Hoffman RE. Individual and Community Risks of Measles and Pertussis associated with Personal Exemptions to Immunization. JAMA 2000; 284: 3145-3150.
15. Shamah R, Bhasin SK. Routine immunization-do people know about it? A study among caretakers of children attending pulse polio immunization in east Delhi. Ind $J$ Comm Med 2008; 33: 31-34.

16. McCormick LK, Batholomew LK, Lewis MJ, Brown MW, Hanson K. Parental perception of barriers to childhood immunization: results of focus groups conducted in an urban population. Hlth Ed Res 1997; 12: 355-362.

17. Kabir M, Iliyasu Z, Abubakar IS, Gajida AU. Knowledge, perception and beliefs of mothers on routine childhood immunization in a Northern Nigerian village. Ann Nig Med 2005; 1: 21-26.
18. Adeyinka DA, Oladimeji O, Adeyinka FE, Aimakhu C. Uptake Of childhood immunization among mothers of under-Five in Southwestern Nigeria. The Internet $J$ Epidemiol. 2009; 7(2): ISSN: 1540 $-2614$.

19. Morrissey L Mosley S, Stewart R, Feeney A, Muravec Z, Meeham J et al. Paed Res 2011; 70: 583-583.

20. WHO. Over 100 countries participate in immunization week. Immunization, Vaccines and Biologicals 2010. Available at www.who.int/ entity/immunization/newsroom/ adv cacy_events_immunization_weeks _2010/en/. Accessed 08/01/2012. 